\title{
Historical background of melioidosis
}

\author{
D Dance D,2,3 $^{1,3}$
}

Melioidosis was first recognised by Alfred Whitmore and his assistant CS Krishnaswamy working in Rangoon, Burma (now Myanmar) in 1911. The first two decades of research on Whitmore's bacillus was dominated by British workers in Burma and the Federated Malay States, particularly Stanton and Fletcher at the Institute for Medical Research in Kuala Lumpur, who first coined the term 'melioidosis'. During the 1920s and '30s, the disease was found also to be present in other British, French and Dutch colonies in Asia, with the first case in the Indian sub-continent reported from Sri Lanka in 1927.

The demonstration that Burkholderiapseudomalle $i$ was present in the environment by researchers in French Indochina in the 1930s and 1950s completely changed our understanding of its epidemiology. From the 1940s-1970s the known global distribution was gradually extended, with the first cases from India reported in 1953, Australia in 1949, Thailand in 1955 and Bangladesh in 1964. The disease came to prominence as a cause of infection amongst French and American troops during the Vietnam conflicts, and began to attract attention from both the USA and USSR as a potential bioweapon around that time. The later designation of the organism as a Select Agent in the USA has given welcome impetus (and additional funding) to research into all aspects of melioidosis.

During the 1980s, the true burden of melioidosis in countries in SE Asia began to become apparent, enabling a series of clinical trials to be undertaken in Thailand that have defined modern therapeutic regimens. The publication of the first B. pseudomallei genome sequence in 2004, and the rapid development of genomics, have created opportunities for rapid progress in our understanding of the basic biology, epidemiology and pathogenesis of melioidosis, as well as vaccine development.

However, if the burden of melioidosis, which is thought to infect at least 165,000 people and cause 89,000 deaths per year worldwide, the brunt of which is thought to be borne by the Indian sub-continent, is to be reduced, the key will be to increase awareness of the disease, extend the coverage of basic microbiology services, and develop simple public health programmes that reduce exposure of vulnerable people such as diabetics to infection.

\footnotetext{
${ }^{1}$ Lao Oxford Mahosot Hospital Wellcome Trust Research Unit, Lao PDR/Centre for Tropical Medicine, Laos.

${ }^{2}$ University of Oxford, UK.

${ }^{3}$ London School of Hygiene and Tropical Medicine, UK.

Address for correspondence: Prof David Dance, Lao Oxford Mahosot Hospital Wellcome Trust Research Unit, Lao PDR/Centre for Tropical Medicine, Laos.+8562077475588 Email: david.d@tropmedres.ac

(D) https://orcid.org/0000-0001-9189-7244
} 